Keywords: Crinoids; species delimitation; Southern Ocean; cryptic species; Florometra

\section{The rapid divergence of the Antarctic crinoid species Promachocrinus kerguelensis}

Running title: Phylogeography of Antarctic crinoids Yacine Ben Chehida ${ }^{1,2 *}$, Marc Eléaume ${ }^{1}$, Cyril Gallut ${ }^{1}$, Guillaume Achaz ${ }^{1,3}$

${ }^{1}$ Institut de Systématique, Évolution, Biodiversité (ISYEB), Muséum national d'Histoire naturelle, CNRS, Sorbonne Université, EPHE, Université des Antilles. 57 rue Cuvier, CP 50, 75005, Paris, France;

${ }^{2}$ University of Groningen: Groningen Institute for Evolutionary Life Sciences (GELIFES), University of Groningen, PO Box 11103 CC, Groningen, The Netherlands;

${ }^{3}$ Stochastic Models for the Inference of Life Evolution, CIRB (UMR 7241 CNRS), Collège de France, Paris, France.

* Correspondence: Yacine Ben Chehida (h.y.ben.chehida@rug.nl). University of Groningen: Groningen Institute for Evolutionary Life Sciences (GELIFES), University of Groningen, PO Box 11103 CC, Groningen, The Netherlands. mawsoni; speciation; Promachocrinus kergulensis; "apparent" drift; recent divergence 


\section{Abstract}

35 Climatic oscillations in Antarctica caused a succession of expansion and reduction of the ice

36 sheets covering the continental shelf of the Southern Ocean. For marine invertebrates, these

37 successions are suspected to have driven allopatric speciation, endemism and the prevalence

38 of cryptic species, leading to the so-called Antarctic 'biodiversity pump' hypothesis. Here we

39 took advantage of the recent sampling effort influenced by the International Polar Year (2007-

40 8) to test for the validity of this hypothesis for 1,797 samples of two recognized crinoid

41 species: Promachocrinus kerguelensis and Florometra mawsoni. Species delimitation

42 analysis identified seven phylogroups. As previously suggested, Promachocrinus kerguelensis

43 forms a complex of six cryptic species. Conversely, despite the morphological differences,

44 our results show that Florometra mawsoni is a lineage nested within Promachocrinus

45 kerguelensis. It suggests that Florometra mawsoni and Promachocrinus kerguelensis belong

46 to the same complex of species. Furthermore, this study indicates that over time and space the

47 different sectors of the Southern Ocean show a remarkable rapid turn-over in term of

48 phylogroups composition and also of genetic variants within phylogroups. We argue that

49 strong "apparent" genetic drift causes this rapid genetic turn-over. Finally, we dated the last

50 common ancestor of all phylogroups at less than 1,000 years, raising doubts on the relevance

51 of the Antarctic "biodiversity pump" for this complex of species. This work is a first step

52 towards a better understanding of how life is diversifying in the Southern Ocean. 


\section{Introduction}

During the last decade following the last International Polar Year (2007-8) a huge effort has been made to better understand Antarctic marine ecosystems and one of the major outcomes has been the creation of a reference barcode database (BOLD) that reconciles morphologically recognized species with a unique COI fragment. This opened to a new era of discoveries that allowed reassess some of the main known characteristics of marine Antarctic ecosystems, including eurybathy, excess in brooding species, high rate of endemism, rapid diversification and cryptic speciation as a consequence of the biodiversity pump (Clarke \& Crame, 1989). Recent biodiversity assessments using molecular tools have revealed an increasing number of cryptic species in teleost fishes as well as Echinodermata, Mollusca, Arthropoda, or Annelida (see (Cornils \& Held, 2014; Griffiths, 2010; Rogers, 2007) for comprehensive reviews). Cryptic species have been shown to be homogeneously distributed among taxa and biogeographic regions (Pfenninger \& Schwenk, 2007) and Antarctica may well be no exception.

The Southern Ocean is known to have undergone several glaciation events (Clarke \& Crame, 1989; Clarke, Crame, Stromberg, \& Barker, 1992; Thatje, Hillenbrand, Mackensen, \& Larter, 2008). Massive ice sheet advance and retreat seem to have bulldozed the entire continental shelf several times during the last 25 Mya. These events are thought to be driven by Milankovitch cycles. These cycles may be among the strongest evolutionary forces that have shaped Antarctic terrestrial and marine biodiversity (Clarke et al., 1992; Thatje et al., 2008; Thatje, Hillenbrand, \& Larter, 2005). Thatje et al. (2005; 2008) hypothesized that vicariant speciation could have occurred during the glacial periods on the Antarctic continental shelf, within multiple ice-free refugia like polynya. As lineages evolved independently during the glacial period, they accumulated genetic differences that lead to reproductive isolation and probably to the formation of cryptic species. During interglacial periods, barriers to gene flow may have been removed allowing for secondary contact between the vicarious lineages

80 (Heimeier, Lavery, \& Sewell, 2010; Thatje et al., 2005; 2008; Thornhill, Mahon, Norenburg, $\&$ Halanych, 2008). An alternative hypothesis is based on the idea that Antarctic continental shelf may be understood as a species flock generator (Eastman \& McCune, 2000; Lecointre et al., 2013). 
Promachocrinus kerguelensis (Carpenter, 1888) and Florometra mawsoni (AH Clark, 1937), endemic to the Southern Ocean. These species represent the most abundant crinoid species in the Southern Ocean (Eléaume, Hemery, Roux, \& Améziane, 2014; Speel \& Dearborn, 1983). They are morphologically distinct (but see (Eléaume, 2006) for counter arguments) and genetically close (Hemery, Améziane, \& Eléaume, 2013a). These species are thought to have a reproduction cycle that involves external fertilization that could result in a large dispersal potential. P. kerguelensis produces positively buoyant ovocytes that, after fertilization, may remain in the plankton for weeks or even months (McClintock \& Pearse, 1987). Some adults of $P$. kerguelensis have also been observed swimming (Eléaume, unpublished observations), and some adults of F. mawsoni, though never observed swimming in situ, have shown this ability in tanks (Eléaume, unpublished observations).

During the last decade, numerous specimens of crinoids have been collected from all around Antarctica and sub-Antarctic islands. Over 3,000 specimens attributed to 45 species have been sampled (Eléaume et al., 2014). Species such as Promachocrinus kerguelensis and Florometra mawsoni are represented by a large number of well distributed specimens. Knowlton $(1993 ; 2000)$ predicted for Southern Ocean organisms that an increase in sampling effort and the application of genetic tools, would reveal cryptic species. The analysis of P. kerguelensis COI barcode fragment suggested that this species may constitute such an example of a complex of unrecognized species. Wilson et al. (2007) identified six lineages in the Atlantic sector whereas Hemery et al. (2012) extending the analysis of Wilson to the entire Southern Ocean, identified seven lineages. As no obvious morphological character have been shown to distinguish between these lineages (Eléaume, 2006), they may represent true cryptic species. However, Hemery et al. (2012) using nuclear markers have shown that the six identified COI lineages may only represent three distinct entities. All of the six or seven lineages are circumpolar in distribution, sympatric and eurybathic but show various levels of connectivity that depend on the lineage and the geographical area.

Here we analyze the pooled COI datasets of P. kerguelensis and F. mawsoni of Wilson et al. (2007) and Hemery et al. (2012) using different approaches to separate different sources of genetic variation, i.e. differences due to diversification (clade), time (year collected), space (geographical origin of samples). We first analyze the phylogenetic relationships within P. kerguelensis sensu largo using different species delineation methods. We then measure the genetic turn-over, within each phylogroup sampled at a given location. Using a population genetics coalescent framework, we estimated an extraordinary small effective population size 
bioRxiv preprint doi: https://doi.org/10.1101/666248; this version posted June 12, 2019. The copyright holder for this preprint (which was

not certified by peer review) is the author/funder, who has granted bioRxiv a license to display the preprint in perpetuity. It is made available under aCC-BY-NC-ND 4.0 International license.

118 that corresponds to a mutation rate that is larger than previously reported before. We then

119 discuss our results in the light of the climate history of the Southern Ocean. 


\section{Materials and methods}

\section{Sequences}

123 We included 13 sequences of P. kerguelensis from Wilson et al. (2007), for which we had 124 precise information about the place and the date of sampling. We have also included 1303 125 sequences of P. kerguelensis from Hemery et al. (2012) together with 479 sequences of 126 F. mawsoni (Hemery et al., in preparation). A total of 1,797 COI sequences were used for this 127 study. All specimens were collected between 1996 and 2010 in seven geographical regions 128 that were described in Hemery et al. (Hemery et al., 2012): Kerguelen Plateau (KP), Davis 129 Sea (DS), Terre Adélie (TA), Ross Sea (RS), Amundsen Sea (AS), West Antarctic Peninsula 130 (WAP), East Weddell Sea (EWS). We however further split the Scotia Arc into Scotia Arc 131 East (SAE) and Scotia Arc West (SAW) as there can be as much as 2,000 km between them.

132 The counts of all sequences of all locations are reported in Table S1.

\section{DNA extraction, PCR and sequencing}

134 For this analysis, no additional sequences have been produced. For DNA extraction and PCR 135 procedures see (Hemery et al., 2012; Wilson et al., 2007) and 2013. A total of 1797 554-bp sequences of the barcode region of cytochrome c oxidase subunit I (COI) were amplified using the Folmer et al. (1994) primers and other specific primers described in Hemery et al. (2012). All COI sequences from Hemery et al. (2012) have been made easily available through a data paper article (Hemery et al., 2013a).

\section{Species delimitation}

141 We used three independent species delimitation methods: Generalized Mixed Yule Coalescent 142 (GYMC, (Pons et al., 2006)), Automatic Barcode Gap Discovery (ABGD, (Puillandre, 143 Lambert, Brouillet, \& Achaz, 2011)) and Poisson Tree Process (PTP, (Zhang, Kapli, Pavlidis, $144 \&$ Stamatakis, 2013)) to estimate the number of phylogroups in our sample. For all these 145 methods, we used all the 199 unique haplotypes of the dataset to have legible results and a 146 faster computation time. The phylogenetic tree used for PTP was constructed by Neighbor 147 Joining method the BioNJ implementation (Gascuel, 1997) in Seaview software (Gouy, 148 Guindon, \& Gascuel, 2010) version 3.2. PTP analysis was conducted online (http://species.h149 its.org/ptp/). The ultrametric tree needed for GYMC method was constructed using BEAST 150 software (Bayesian Evolutionary Analysis Sampling Trees, (Drummond, Suchard, Xie, \& 
151 Rambaut, 2012) version 1.7). GYMC analysis was conducted online (http://species.h-

152 its.org/gmyc/). ABGD analysis was conducted online

153 (http://wwwabi.snv.jussieu.fr/public/abgd/abgdweb.html).

\section{Assessing the temporal structure within phylogroups}

155 We characterized the temporal structures of our samples in pairwise comparisons using both 156 fixation index $F_{S T}$ as well as a non-parametric structure test based on $K^{*_{S}}$ by Hudson et al. 157 (1992). All p-values were estimated using permutations as described in Hudson et al. (1992). 158 A web-interface for the latter can be found at http://wwwabi.snv.jussieu.fr/public/mpweb/.

\section{Estimation of the mutation rate and the population effective size}

160 As described by $\mathrm{Fu}$ (2001) one can use temporal data to estimate the mutation rate $(\mu)$. In 161 summary, the method assumes that the population is sampled in at least two time points (say $162 T_{1}$ and then later $T_{2}$ ) with multiple sequences in $T_{1}$. The expected average pairwise differences 163 between sequences taken from the two time points $\left(K_{12}\right)$ equals the average pairwise 164 differences of sequences within the past time point $\left(K_{11}\right)$ plus the difference accumulated since then. Mathematically, it is expressed as $E\left[K_{12}\right]=E\left[K_{11}\right]+\left(T_{2}-T_{1}\right) \mu$. Because the time difference between the samples $\left(T_{2}-T_{1}\right)$ is known, the mutation rate can be estimated from the observed pairwise differences: $\mu=\left(K_{12}-K_{11}\right) /\left(T_{2}-T_{1}\right)$. This idea can be expanded when more data are available in other time points (Fu, 2001).

169 Once $\mu$ is known, the average pairwise difference can be used to estimate the effective 170 population size $(\mathrm{Ne})$. Under the standard neutral model, the pairwise difference within groups 171 of the same sample equals $2 N e \mu$, when $\mu$ is expressed as a rate by generations. Here, we assumed one generation every three year to estimate $\mathrm{Ne}$ (Clark, 1921).

\section{Estimation of the time of divergence between phylogroups}

174 For visualization purposes, an ultrametric tree was constructed with the unique sequences by 175 UPMGA (Michener \& Sokal, 1957) as implemented in the Phylip package (Felsenstein, 1989)

176 version 3.6. Using the estimated mutation rate, we derived a time of divergence within and between phylogroups from the average sequence differences. 


\section{Polymorphisms analysis}

180 We used Dnasp software version 5.10 (Librado \& Rozas, 2009) and the program used to

181 study genetic structure to study the SFS (Site Frequency Spectrum) within phylogroups as

182 well as two of its summary statistics: nucleotide diversity $(\pi)$ and number of polymorphic 183 sites (S). We then tested neutrality using Tajima's D (Tajima, 1989), Fu and Li's F* and D* 184 (Fu \& Li, 1993), Achaz's Y* (Achaz, 2008), that is immune to sequencing errors, and the 185 Strobeck (Strobeck, 1987) haplotype test.

Assessment of migration effect on Ne estimation through simulations

187 To assess the potential effect of migrants from a distant population on the estimation of $\mu$ and $188 \mathrm{Ne}$, we used coalescent simulations where two samples of 20 sequences each are taken $3 \mathrm{~N}$ 189 generations apart in a focal population of size $N$. We assume a large unsampled ghost 190 population of size $10 N$ that exchange migrants with the focal one at rate $M=4 N m$, where $m$ is 191 the migration rate per generation. For values of $M$ ranging from 0.001 (very low) to 1000 192 (very large), we applied the $\mathrm{Fu}(\mathrm{Fu}, 2001)$ method to estimate $\mathrm{Ne}$, with $10^{3}$ replicates for each $193 M$ value. The program is based on a $\mathrm{C}++$ library developed by $\mathrm{G}$. Achaz that is available upon 194 request. 


\section{Results}

\section{P. kerguelensis and F. mawsoni are composed of seven phylogroups}

197 We first reinvestigated the species delimitation of the sample using three independent 198 approaches (GMYC, ABGD and PTP) that cluster the unique sequences by phylogroup. We 199 adopt in this manuscript a nominalist definition of species. However, F. mawsoni, a nominal 200 species, is nested within P. kerguelensis, another nominal species, lineages. To avoid 201 confusion, we have decided to use the term "phylogroup" in the rest of the manuscript to designate any well-supported cluster of sequences derived from species delineation approaches.

204 Two of the three methods estimate a similar number of phylogroups: PTP estimates that there 205 are nine phylogroups in the sample whereas ABGD reports 5-7 phylogroups, depending on 206 the chosen prior value. Looking at the proposed partitions, we have chosen to consider seven 207 different phylogroups for this study that are reported as phylogroups A-G in Fig. 1. 208 Interestingly, these phylogroups correspond to the A-F groups proposed by Wilson et al. 209 (2007), plus a 'new' group (G) that corresponds to the $F$. mawsoni species. The two extra sub210 splits suggested by the PTP method are indicated as $\mathrm{C} 1 / \mathrm{C} 2$ and E1/E2 on Fig. 1. Note that 211 PTP only seeks monophyletic groups and thus must split the $\mathrm{C}$ group into the $\mathrm{C} 1 / \mathrm{C} 2$ 212 subgroups.

213 In contrast with the two previous methods, depending on the sequence evolution model we 214 used and the BEAST parameters, GMYC reports between 3 and 51 phylogroups with non215 overlapping grouping between individuals. As GMYC is very sensitive in our case to the 216 chosen parameters, it is here unreliable and we chose to not consider the GMYC partitions.

217 Genetic distance between phylogroups are similar to the distance of each phylogroup to the $\mathrm{G}$ 218 group. However, $\mathrm{G}$ group corresponds to a nominal species (F. mawsoni) which suggests that 219 the A-G phylogroups could correspond to seven different yet undescribed species.

\section{A very rapid local turn-over}

221 Relative abundance of phylogroups: Two of the analyzed locations (Ross Sea and East 222 Weddell Sea) were densely sampled (at least 50 sequences) at two (or more) different time 223 points. We therefore took advantage of these time series to evaluate the turnover of the 224 resident crinoids from year to year. The analysis of the relative abundance of the various 
phylogroups shows that for both locations the genetic composition is highly unstable through time (Fig. 2a and 2c). Phylogroup composition in EWS is stable from 1996 to 2004, and changes drastically in 2005 when phylogroup $C$ has not been sampled. This pattern leads to a highly significant difference between all years (Fisher exact test, $\mathrm{P}=4.710^{-10}$ ). Similarly, the composition of the RS location is also highly significantly different between 2004 and 2008 (Fisher exact test, $\mathrm{P}=3.210^{-11}$ ); in this case, phylogroup A is replaced by phylogroups $\mathrm{B}$ and E.

232 Other locations display a single sampling event (AS, DS, TA) or reduced number of 233 sequences over several sampling events (e.g. SAW: 2 sequences in 2000, 11 in 2002, 7 in 2342006 and 68 in 2009), and cannot be used to robustly assess the stability of phylogroup 235 relative abundance.

236 Turn-over within the phylogroups: We then measured the replacement of genetic variants 237 within the phylogroups. To do so, we considered samples with at least 10 sequences of the 238 same phylogroup in the same location at two different time points. The pairwise comparisons 239 for such groups are all reported in Table 1 and we provide two graphical representations for 240 phylogroup D in the RS location (Fig. 2b) and phylogroup C in the EWS location (Fig. 2d). In 241 two cases (phylogroup C in EWS and phylogroup D in RS), we found a significant difference 242 in the genetic composition within each phylogroups even when they are separated by only few 243 years, again suggesting an unexpectedly high turn-over of the genetic pool of these crinoids. 244 Interestingly, the temporal differentiation of phylogroup E within EWS is already $F_{S T}=4 \%$ in 245 four years, that is not significant because of the small sample size (10 and 11 respectively). 246 Only the two samples of phylogroup G in EWS, that are separated by a single year, show no 247 sign of temporal differentiation $\left(F_{S T}=1 \%\right)$.

\section{Estimation of the mutation rate and the effective population size}

249 Using the robust yet elegant approach devised by $\mathrm{Fu}$ (2001), we estimated the yearly mutation 250 rates $(\mu)$ from the same sample comparisons (i.e. phylogroups with two or more samples of 10 251 or more sequences within the same location). Furthermore, we also estimated the 252 corresponding effective population size $(\mathrm{Ne})$ assuming a generation time of three years. 253 Results (Table 2) shows that all estimated mutation rates are $10^{-5}-10^{-4} / \mathrm{bp} /$ year, with a mean 254 of $8.10^{-5} / \mathrm{bp} /$ year. Results also show that the effective sizes are very low, on the order of 2-7 255 (Table 2). The very low effective size corresponds to the unexpected high turn-over of the 256 genetic pool that we observe within the phylogroup at the same location. 


\section{Polymorphism analysis}

258 For samples of 10 sequences or more (with the same year and same location), we have 259 analyzed the characteristics of segregating polymorphisms using four neutrality tests: 260 Tajima's D (Tajima, 1989), Fu and Li's F* and D* (Fu \& Li, 1993), Achaz's Y* (Achaz, 261 2008) and Strobeck P-values (Strobeck, 1987). Results (Fig. 3) show almost no deviation 262 from the standard neutral model, except for the $\mathrm{Fu}$ and Li's $\mathrm{F}^{*}$ and $\mathrm{D}^{*}$. This statistics points 263 to a clear excess of singletons. However, singletons likely contain sequencing errors that 264 strongly skew these statistics (Achaz, 2008). The Y statistics that ignores singletons exhibits a 265 distribution that is very close to the one expected under the standard neutral model. We 266 therefore conclude that the observed polymorphisms suggest that basic assumptions of the 267 standard neutral model (i.e. constant population size, no migration, no structure and no 268 selection) cannot be rejected for these crinoid phylogroups.

\section{Assessing the effect of migration using simulations}

To test whether migration could accelerate the genetic turn-over of a species on a given location, we studied a simple model where the sampled location exchanges migrants with a

272 large pool of panmictic individuals. One expects that a constant arrival of migrants from this 273 large pool could interfere with the estimation of effective size. We thus simulated a model 274 where the sampled population has a size $N$ and the pool $10 N$. We studied the impact of the 275 migration rate on the estimation of Ne using the same method than above (2001). Results (Fig. 276 4) show that at low migration rate, the estimator is unaffected whereas it is inflated up to $11 \mathrm{~N}$ 277 at high migration rate. This shows that the existence of a large pool from where migrants can 278 come into the sampled population can only inflate the estimation of $\mathrm{Ne}$ and therefore cannot 279 explain the low $\mathrm{Ne}$ we have estimated.

\section{Phylogroups divergence}

281 We then computed an estimate for the times of split between the seven phylogroups using our population genetics estimation of the mutation rate $\left(8.10^{-5}\right.$ mutations $/ \mathrm{bp} /$ year $)$. Our estimates are reported in an ultrametric tree (Fig. 5) where the oldest split between the phylogroups is estimated around 400 years. This very short time scale is in sharp contrast with the millions of years of previous estimations based on other estimated mutation rates $\left(3.10^{-8}\right.$ mutations $/ \mathrm{bp}$ /year) that were based on echinoderms thought to be separated by the formation of the panama isthmus (Lessios, Kessing, Robertson, \& Paulay, 1999). 


\section{Discussion}

\section{Speciation in Antarctica: the classical view}

290 Due to its extreme environmental conditions, it has been hypothesized that climate driven 291 evolution in Southern Ocean has been more important than in other ecosystems where 292 ecological interactions play a larger role (Rogers, 2012). The diversity and the distribution of 293 many marine taxa in Antarctica has been strongly shaped by climate variation and continental 294 drift leading to dispersal, vicariance and extinction since the break-up of Gondwana 295 (Williams, Reid, \& Littlewood, 2003). Indeed, the global climate change at the end of the 296 Eocene related to the continental drift is characteristic of the transition from a temperate 297 climate to the current polar climate in Antarctica (Clarke et al., 1992; Clarke \& Crame, 1989). 298 The physical separation of Antarctica, South America and Australia resulted in the cooling of 299 the Southern Ocean, which in turn initiated the physical and climate isolation of this region of 300 the world (Tripati, Backman, Elderfield, \& Ferretti, 2005). This isolation was followed by an 301 extensive continental glaciations and the initiation of the Antarctic Circumpolar Current in the 302 Miocene (Clarke et al., 1992; Clarke \& Crame, 1989; Thatje et al., 2008). These two processes exacerbated the environmental and biological isolation of the Southern Ocean and are classically recognized as the main explanation to the high level of endemism observed in Antarctica (Clarke \& Crame, 1989; Griffiths, Barnes, \& Linse, 2009).

The Quaternary was marked by the oscillation of glaciation and interglacial periods, which strongly affected the ice cover present in Antarctica (Davies, Hambrey, Smellie, Carrivick, \& Glasser, 2012). These cycles led to severe temperature oscillations and to the succession of

309 large extensions of the ice sheets on the continental shelf followed by retreats of the ice sheets.

310 They have been one of the main drivers of the diversification of species in Antarctica. Indeed,

311 the isolation of populations in ice free refugia during the glacial era, such as polynya or in the 312 deep sea, has been suggested as a mechanism of fragmentation of populations leading to 313 allopatric speciation in the Southern Ocean. This process is called the Antarctic 'biodiversity 314 pump' (Clarke et al., 1992; Clarke \& Crame, 1989). The Antarctic 'biodiversity pump' has 315 been proposed to be the main mechanism driving speciation and diversification in Antarctica.

316 Our knowledge on evolutionary history of Antarctic fauna was classically derived from 317 studies of the systematics and distribution of marine animals relying heavily on the 318 morphology of present and past (fossil) organisms. Such approaches are limited for two main 
reasons. First, species morphology may not reflect the true evolutionary relationships between taxa (DeBiasse \& Hellberg, 2015). Second, several periods of time lack a reliable fossil record. Today, the emergence of molecular approaches provides a powerful tool to circumvent these limitations. To this regard, the increasing number of phylogeographic studies allow to get a better understanding of the effects of past changes on the current diversity and spatial distribution of organisms (Allcock \& Strugnell, 2012). They also allow to accurately assess the distribution of genetic diversity within and among species. Such information is extremely valuable to evaluate and mitigate the impacts of human-induced activities on the biodiversity of the Southern Ocean (Chown et al., 2015). This study take place in this context and by expanding the results of two previous studies (Hemery et al., 2012; Wilson et al., 2007), we aimed to determine the drivers of the diversity of two crinoid taxa in the Southern Ocean, P. kerguelensis and F. mawsoni.

\section{The concept of species: is Promachocrinus kerguelensis a complex of multiple} cryptic species?

334 The analysis of 1797 sequences using recent species delimitation approaches allowed to identify seven operational taxonomic units. We confirmed the presence of six phylogroups (A-F) identified in two previous study (Hemery et al., 2012; Wilson et al., 2007), but only the PTP method supports the further split between E1 and E2 suggested by Hemery et al. (2012).

338 Furthermore, despite their strong morphological differences and monophyly (Fig. 1), our results strongly suggest that F. mawsoni (phylogroup G) belongs to the P. kerguelensis complex. Indeed, the reciprocal monophyly of $G$ and $F$ and the proximity of $E$ to $G / F$ compare to A-D confirm the affiliation of $\mathrm{G}$ as a member of $P$. kerguelensis complex (Fig. 1). Therefore, we corroborated Hemery et al. (2012) results showing that P. kerguelensis consists in a complex of several cryptic species. We also confirmed Eléaume (2006) conclusion that

344 despite striking exterior morphological differences phylogroup $\mathrm{G}$ is also a member of this complex of species, and Hemery et al. (2013b) results based on a multi-markers phylogenetic reconstruction.

347 Morphological similarities between cryptic species often reflect a recent speciation event 348 (Bickford et al., 2007). In the marine realm, speciation is less associated to morphology than 349 to other phenotypic aspects such as chemical recognition systems (Palumbi, 1994). Knowlton 350 (1993) argued that marine habitats are likely to be filled with cryptic species although rarely 
recognized due to limited access to marine habitats. Molecular approaches can be particularly powerful in detecting cryptic species on the basis of their molecular divergence, and recent molecular studies helped reveal the prevalence of cryptic species (See for example (Brasier et al., 2016; Grant, Griffiths, Steinke, Wadley, \& Linse, 2010)). This is particularly the case in the Southern Ocean where numerous molecular studies have suggested the presence of cryptic species (Baird, Miller, \& Stark, 2011; Brasier et al., 2016; Grant et al., 2010; Wilson, Schrödl, \& Halanych, 2009) with areas such as the Scotia Arc representing potential hotspots of cryptic diversity (Linse, Cope, Lörz, \& Sands, 2007). The prevalence of invertebrate cryptic species in the Southern Ocean is probably due to the cyclical variation of ice sheets extent in Antarctica during repeated glacial and interglacial periods which could have fostered the separation of population, promoting genetic divergence and allopatric cryptic speciation (Clarke \& Crame, 1989). During glacial periods, ice sheets extension is thought to have forced marine species inhabiting the continental shelf to take refuge in the deep sea or in shelf refugia, such as areas where permanent polynyas (Thatje et al., 2008) occurred. During glacial maxima the decrease of gene flow between populations would have promoted reproductive isolation and increased genetic variation between populations. Under glacial maximum extreme environmental conditions, a potential increase of the diverging selective pressures on behavioral and physiological characters rather than morphology (which could be under strong stabilizing selection), could lead to a reduction of the morphological changes usually associated with speciation (Fišer, Robinson, \& Malard, 2018). In such a scenario, high levels of divergence are expected on neutrally evolving genes as observed in this study. This process might explain the high number of cryptic species reported in the Southern Ocean.

373 The concept of species is controversial in biology as there is no unique definition that can be 374 applied to all species under all circumstances (Mayden, 1997). Here, the application of species delimitation methods (based on the genetic concept of species) using molecular tools identified six highly divergent lineages indiscernible on the basis of their morphology and a last morphologically divergent lineage. Therefore, this study show how the use of molecular data can provide new insights into the nature of the genetic boundaries between species (Pante et al., 2015). However, in the light of these findings we can wonder what do the lineages highlighted in this study represent? Are they genuine different species? Here the use of different criteria to delineate species based on reproductive isolation (biological concepts of species) or on morphology (morphological concept of species) will probably lead to the identification of a different number of species (Fišer et al., 2018). This is a good illustration of 
the "species problem" and stress out the fact that the notion of species itself is an abstract concept that should be questioned (De Queiroz, 2007). It has also important consequences in term of the protection of the biodiversity because disparate groupings of species will in turn result in different economic implications and conservation decisions (Frankham et al., 2012).

\section{A remarkably fast turn over and low effective population sizes}

390 This study indicates that over time the different sectors of the Southern Ocean show a 391 remarkable turn over in term of phylogroup composition. For example, in less than a decade, 392 the Ross and East Weddell Sea phylogroups composition changed substantially (Fig 2a and 393 2c). A, B and F may or may not be sampled from one year to the next, whereas $C, D$ and $G$ 394 are always present but their proportions change drastically (Fig 2a and 2c). This observation suggests that within the same geographical region, the real number of individual per phylogroup varies considerably over time. One hypothesis that could explain these patterns is the presence of strong marine currents (such as the ACC, Ross Gyre and Weddell Gyre) mixing individuals and thus changing continuously their distribution across the Southern Ocean over time. A similar mechanism has been evoked to explain the current diversity and the distribution of sponges across the Southern Ocean (Downey, Griffiths, Linse, \& Janussen, 2012).

402 Furthermore, within phylogroups, in a few years, the genetic makeup can change significantly. 403 For instance, the genetic composition of the phylogroup $\mathrm{C}$ and $\mathrm{D}$ changed totally between 4041996 and 2008, respectively in the East Weddell Sea and Ross Sea (Fig. 2b, d). Such spatio405 temporal variations in term of genetic composition could also be attributed to marine currents that constantly shuffle individuals between populations. Over time, the constant arrival of 407 individuals stemming from different populations continually modify the observed genetic composition within the same geographical location.

409 Alternatively, a rapid divergence of the genetic pool by genetic drift, or any other population 410 processes, could also explain this rapid genetic turn over. The low effective population sizes 411 highlighted in this study $(N e<10$; Table 2$)$ are also consistent with this pattern. Indeed, lower 412 values of $\mathrm{Ne}$ are associated with increased amount of "apparent" genetic drift. Furthermore, 413 isolated populations are expected to diverge inversely proportional to their effective 414 population sizes. Therefore, when the effective population sizes are extremely low, 
415 populations can significantly diverge from each other in just a few generations (Hudson \& 416 Coyne, 2002).

417 The simulations conducted in this study (Fig. 4) show that gene flow from an unsampled 418 reservoir should inflate the $\mathrm{Ne}$ values estimated with the method of $\mathrm{Fu}(\mathrm{Fu}, 2001)$. Therefore, 419 due to the extremely low value of $\mathrm{Ne}$ observed, the hypothesis of a rapid divergence by "apparent" genetic drift is favored here over the hypothesis of a rapid divergence mediated by marine current continually modifying the genetic pool of the populations.

422 It is also important to bear in mind that our estimates of $\mathrm{Ne}$ depend directly on the number of 423 generations per year $(\mathrm{Fu}, 2001)$. In Table 2, we assumed a generation time of three year, 424 however if for example we assumed a generation time of 30 years, our estimates of $\mathrm{Ne}$ would increase tenfold. In our case, depending on the assumed value of the generation time, the interpretation of the $\mathrm{Ne}$ could change accordingly.

427 Overall, the Ne values estimated in this study for the P. kerguelensis and F. mawsoni are low. 428 However, they are highly abundant in the Southern Ocean (Hemery et al., 2013a; McClintock 429 \& Pearse, 1987) which is indicative of a high census size. Such a discrepancy between the 430 census $(\mathrm{Nc})$ and effective $(\mathrm{Ne})$ population size is commonly observed in nature, especially for 431 marine species with large size (Filatov, 2019). However, the reasons behind it are not always 432 clear (Filatov, 2019; Palstra \& Fraser, 2012). At least four biological phenomena could cause $433 N c$ and $N e$ to be different in P. kerguelensis complex (with $N e<<N c$ ). First, an unequal sex 434 ratio, i.e. an uneven number of males and females contributing to the next generation, lead the rarer sex to have a greater effect on genetic drift which decreases $N e$ compare to $N c$. Although 436 this hypothesis is plausible, to this day the sex ratio of P. kerguelensis and F. mawsoni 437 remains unknown. Furthermore, the sex-ratio distortion would need to be extreme to reach 438 such a low $N e$. Second, a fluctuation of $N c$ over time can affect the ratio between $N e$ and $N c$. 439 Indeed, an estimate of $N e$ over several generations is the harmonic mean of $N c$ over time. 440 Therefore, if $N c$ changes substantially over time, $N e$ is typically smaller than Nc. Fig. 2 441 indicates that the proportion of $P$. kerguelensis and F. mawsoni lineages can vary radically 442 from year to year and thus the fluctuation of $N c$ over time for each lineage can change 443 consequently leading $N e$ to be smaller than $N c$. Third, the reproductive strategy of $P$. 444 kerguelensis and $F$. mawsoni can participate to reduce $N e$ compared to $N c$. Indeed, when 445 individuals contribute unequally to the progeny of the next generation, a great proportion of 446 the next generation comes from a small number of individuals which reduces $\mathrm{Ne}$. Due to its 
mode of reproduction, $P$. kerguelensis is particularly incline to have a very reduced number of individuals contributing disproportionately to the progeny. Reproduction occurs synchronously around the months of November and December where males and females spawn and due to the dispersion of gametes by currents, a very small proportion of individuals have their ovocytes fertilized (McClintock \& Pearse, 1987). Therefore, only a very small part of the produced larvae contributes effectively to the gene pool. This phenomenon can drastically reduce $N e$ compare to $N c$ and has been reported in different spawning species (Lind, Evans, Knauer, Taylor, \& Jerry, 2009). This mode of reproduction can also explain the spatio-temporal genetic turn over mentioned previously. Lastly, due to its haploid and uniparental nature, the $\mathrm{Ne}$ of the mtDNA is known to be four times smaller than that of nuclear DNA. Moreover, this effect can be exacerbated by the action of natural selection. Indeed, natural selection can reduce $\mathrm{Ne}$ and the mtDNA is known to be under positive and negative selection (Meiklejohn, Montooth, \& Rand, 2007). Positive natural selection, for example, is expected to reduce the genetic diversity leading to a low Ne (Gossmann, Woolfit, \& EyreWalker, 2011). Indeed, recurrent selective sweeps, related to positive mutations, will reduce the genetic diversity by hitchhiking resulting in a lower $N e$ compared to $N c$. In this regard, Piganeau \& Eyre-Walker (2009) found a strong negative correlation between $\mathrm{Ne}$ and the strength of the natural selection operating on the mtDNA on non-synonymous mutations. In addition, the non-recombining nature of the mtDNA is expected to make this effect even stronger. There are accumulating evidences suggesting that positive natural selection is acting on echinoderm mitogenomes (Castellana, Vicario, \& Saccone, 2011). For example, the strong bias of codon usage observed in the mtDNA of the crinoid species Florometra serratissima compared to many other echinoderms, is also in favor of the idea that some sort of natural selection is occurring, though the mechanism behind it is still not fully understood (Scouras \& Smith, 2001).

\section{Tempo of speciation: Promachocrinus kerguelensis challenges the biodiversity pump hypothesis.}

The mutation rate estimated in this study is approximatively equal to $10^{-5}$ mutations/site/year and is based on population genetics data. Previous estimate of the mutation rate based also on the COI applied to closely related species (Lessios et al., 1999) used a phylogeny based approach and yielded a mutation rate of roughly 3 order of magnitude lower $\left(\approx 10^{-8}\right.$ 
mutations/site/year). Such a discrepancy between mutation rates derived from population data and phylogeny has been already documented (Burridge, Craw, Fletcher, \& Waters, 2008; Madrigal et al., 2012) and is called "time dependency of molecular rates" (Ho et al., 2011; Ho, Phillips, Cooper, \& Drummond, 2005). For example, in human, the mitochondrial D-loop mutation rate derived from pedigree approaches produced an average value of $8.10^{-7}$ mutations/site/year whereas phylogenetic estimates yielded value of $2.10^{-8}$ mutations/site/year (Santos et al., 2005). Likewise, in fishes, Burridge (Burridge et al., 2008) observed a mutation rate of $\approx 10^{-7}$ using a population based approach and $\approx 10^{-8}$ mutations/site/year from a phylogenetic estimates. The potential causes of the "time scale dependency" are reviewed in Ho et al. (2011), but one of the main reason behind it is that population genetics based calibrations lead to estimates reflecting the spontaneous mutation rates, whereas phylogeny based calibrations reflect the substitution rates (i.e. fixed mutations). Therefore, because purifying selection remove the vast majority of the spontaneous deleterious mutations, which constitute a large proportion of them, the spontaneous mutation rate is higher than the substitution rate. Consequently, the rates of molecular evolution decrease with the age of the calibration used to estimate them and it is invalid to assume that a unique molecular clock applies over all time scales (Ho et al., 2005; 2011). A major implication of time dependency is that estimates of recent population divergence times will require re-estimation (Burridge et al., 2008). Therefore, many studies suggesting population isolation related to the Pleistocene glaciations might need to convert these time estimates to more recent ones (i.e. last glacial maximum or Holocene).

Furthermore, the large variation of the mutation rates across the mtDNA regions and between different lineages (Nabholz, Glemin, \& Galtier, 2009), leads the mtDNA to strongly deviate from the molecular clock assumption, which is generally assumed in phylogenetic reconstruction. Therefore, estimates of mtDNA mutation rates relying on phylogenetic approach should be taken with caution (Nabholz et al., 2009; Nabholz, Glemin, \& Galtier, 2008). Conversely, the mutation rate estimated in this study are quite robust as they are model-free ((Fu, 2001); See also Material and Methods). In the case of P. kerguelensis and F. mawsoni, the different mutation rates estimated have important consequences on the age of the separation of the different lineages (Fig. 4). Indeed, the estimate from Lessios et al. (1999) suggest that the split between the different lineages would have occurred in the last million year (Fig. 4), which is congruent with the hypothesis of the biodiversity pump suggesting that most of the speciation events would have occurred during the Quaternary cycles (Clarke et al., 
512 1992; Clarke \& Crame, 1989). Conversely, with our estimate the separation would have

513 occurred in the last 1000 years, implying an extremely recent and rapid diversification for $P$.

$514 \quad$ kerguelensis and F. mawsoni.

515 Explosive radiations have been reported for several taxa (Mahler, Ingram, Revell, \& Losos, 516 2013; Moore \& Robertson, 2014; Muschick, Indermaur, \& Salzburger, 2012) and are, in 517 general, associated with the Pleistocene glacial cycles (Hawlitschek et al., 2012). In contrast, 518 using the molecular rate estimated in this study, in our case the diversification would have 519 happened during the Holocene. Such a remarkably rapid diversification has been rarely 520 recorded in nature (but see Muschick et al., 2012; Peccoud, Simon, McLaughlin, \& Moran, 521 2009). Furthermore, most of rapid radiations reported so far are adaptive and associated to 522 morphological novelties that allow taxa to exploit separate niches. Taxa involved in rapid 523 diversification are generally ecologically/morphologically highly differentiated (Losos \& 524 Miles, 2002). Here, most of the lineages display no obvious morphological differences 525 (except for Florometra) or niche differentiation. As a consequence, the radiation within the $P$. 526 kerguelensis complex is probably mainly nonadaptive (Rundell \& Price, 2009) or adaptive but 527 related to characters that are challenging to distinguish/observe (physiology or behavior). In 528 this context, it is worth noting that structural genomic changes could also drive taxa to rapid 529 adaptive (Kirkpatrick \& Barton, 2006) and nonadaptive (Rowe, Aplin, Baverstock, \& Moritz, 530 2011; Rundell \& Price, 2009) radiation and may represent the mechanism underlying the 531 diversification of the $P$. kerguelensis complex.

532 Finally, the low effective population sizes estimated (Table 2) are congruent with the rapid 533 diversification rate observed. Indeed, Hudson and Coyne (2002) showed that for mtDNA, 534 under the isolation model, two lineages would take between 2 and $3 \mathrm{Ne}$ generations to become 535 reciprocally monophyletic by lineage sorting. Therefore, using the low effective population 536 size estimated in this study (Table 2), it would take a few hundreds of years for two isolated 537 taxa to reach complete reciprocal monophyly. This result is concordant with the divergence 538 observed in this study and contributes to invalidate the Antarctic "biodiversity pump" for the 539 Promachocrinus complex. 


\section{Acknowledgments}

542 The following persons deserve our special thanks for having collected, curated and made

543 available specimens from all around Antarctica: Ty Hibberd (AAD, Hobart), Owen Anderson,

544 David Bowden, Sadie Mills, Kareen Schnabel and Peter Smith (NIWA, Wellington), Stefano

545 Schiaparelli (University of Genoa), Jens Bohn and Eva Lodde (ZSM, Munich), David Barnes,

546 Katrin Linse and Chester Sands (BAS, Cambridge). Our thanks also go to crew and scientists

547 on board various cruises: CEAMARC (IPY project 53), POKERII, TAN08 and AMLR2009

548 cruises. Funding parties also include three Actions Transversales du MNHN: "Biodiversité

549 actuelle et fossile; crises, stress, restaurations et panchronisme: le message systématique”,

550 "Taxonomie moléculaire: DNA Barcode et gestion durable des collections" and

551 "Biominéralisation"; the French Polar Institute IPEV (travel grants to LGH and ME on

552 REVOLTA); This work was supported by the Consortium National de Recherche en

553 Génomique, and the Service de Systématique Moléculaire (SSM) at the MNHN (USM 2700).

554 Part of the molecular work was also supported by collaboration between the Census of

555 Antarctic Marine Life, the Marine Barcode of Life (MarBOL) project and the Canadian

556 Centre for DNA Barcoding (CCDB). DS was supported by funding of the Alfred P. Sloan

557 Foundation to MarBOL. Laboratory analyses on sequences generated at the CCDB were

558 funded by the Government of Canada through Genome Canada and the Ontario Genomics

559 Institute (2008-OGI-ICI-03). We also gratefully thank Lucile Perrier, Charlotte Tarin, Jose

560 Ignacio Carvajal III Patterson (students) and Céline Bonillo (SSM) for their invaluable help in

561 the molecular lab. This work was also funded by the University of Groningen through a $\mathrm{PhD}$

562 fellowship allocated to Yacine Ben Chehida. We also thank Michael C. Fontaine for the

563 logistical support provided during the PhD of Yacine Ben Chehida. 


\section{Literature cited:}

Achaz, G. (2008). Testing for neutrality in samples with sequencing errors. Genetics, 179(3), 1409-1424. http://doi.org/10.1534/genetics.107.082198

Allcock, A. L., \& Strugnell, J. M. (2012). Southern Ocean diversity: new paradigms from molecular ecology. Trends in Ecology \& Evolution, 27(9), 520-528. http://doi.org/10.1016/j.tree.2012.05.009

Baird, H. P., Miller, K. J., \& Stark, J. S. (2011). Evidence of hidden biodiversity, ongoing speciation and diverse patterns of genetic structure in giant Antarctic amphipods. Molecular Ecology, 20(16), 3439-3454. http://doi.org/10.1111/j.1365294X.2011.05173.X

Bickford, D., Lohman, D. J., Sodhi, N. S., Ng, P. K. L., Meier, R., Winker, K., et al. (2007). Cryptic species as a window on diversity and conservation. Trends in Ecology \& Evolution, 22(3), 148-155. http://doi.org/10.1016/j.tree.2006.11.004

Brasier, M. J., Wiklund, H., Neal, L., Jeffreys, R., Linse, K., Ruhl, H., \& Glover, A. G. (2016). DNA barcoding uncovers cryptic diversity in 50\% of deep-sea Antarctic polychaetes. Royal Society Open Science, 3(11), 160432. http://doi.org/10.1098/rsos.160432

Burridge, C. P., Craw, D., Fletcher, D., \& Waters, J. M. (2008). Geological dates and molecular rates: fish DNA sheds light on time dependency. Molecular Biology and Evolution, 25(4), 624-633. http://doi.org/10.1093/molbev/msm271

Castellana, S., Vicario, S., \& Saccone, C. (2011). Evolutionary patterns of the mitochondrial genome in Metazoa: exploring the role of mutation and selection in mitochondrial protein coding genes. Genome Biology and Evolution, 3(3), 1067-1079. http://doi.org/10.1093/gbe/evr040

Chown, S. L., Clarke, A., Fraser, C. I., Cary, S. C., Moon, K. L., \& McGeoch, M. A. (2015). The changing form of Antarctic biodiversity. Nature, 522(7557), 431-438. http://doi.org/10.1038/nature14505

Clark, A. H. (1921). A monograph of the existing crinoids. Bulletin of the United States National Museum, 1(82), 795-949. http://doi.org/10.5479/si.03629236.82.2

Clarke, A., \& Crame, J. A. (1989). The origin of the Southern Ocean marine fauna. Geological Society, London, Special Publications, 47(1), 253-268. http://doi.org/10.1144/GSL.SP.1989.047.01.19

Clarke, A., Crame, J. A., Stromberg, J. O., \& Barker, P. F. (1992). The Southern Ocean Benthic Fauna and Climate Change: A Historical Perspective [and Discussion]. Philosophical Transactions of the Royal Society B: Biological Sciences, 338(1285), 299309. http://doi.org/10.1098/rstb.1992.0150

Cornils, A., \& Held, C. (2014). Evidence of cryptic and pseudocryptic speciation in the Paracalanus parvus species complex (Crustacea, Copepoda, Calanoida). Frontiers in Zoology, 11(1), 19. http://doi.org/10.1186/1742-9994-11-19

Davies, B. J., Hambrey, M. J., Smellie, J. L., Carrivick, J. L., \& Glasser, N. F. (2012). Antarctic Peninsula Ice Sheet evolution during the Cenozoic Era. Quaternary Science Reviews, 31, 30-66. http://doi.org/10.1016/j.quascirev.2011.10.012

De Queiroz, K. (2007). Species Concepts and Species Delimitation. Systematic Biology, 56(6), 879-886. http://doi.org/10.1080/10635150701701083

DeBiasse, M. B., \& Hellberg, M. E. (2015). Discordance between morphological and molecular species boundaries among Caribbean species of the reef sponge Callyspongia. Ecology and Evolution, 5(3), 663-675. http://doi.org/10.1002/ece3.1381

Downey, R. V., Griffiths, H. J., Linse, K., \& Janussen, D. (2012). Diversity and distribution patterns in high southern latitude sponges. PloS One, 7(7), e41672. 

with BEAUti and the BEAST 1.7. Molecular Biology and Evolution, 29(8), 1969-1973. http://doi.org/10.1093/molbev/mss075

Eastman, J. T., \& McCune, A. R. (2000). Fishes on the Antarctic continental shelf: evolution of amarine species flock?*. Journal of Fish Biology, 57(sa), 84-102. http://doi.org/10.1111/j.1095-8649.2000.tb02246.x

Eléaume, M. (2006). Approche morphométrique de la variabilité phénotipique : conséquences systématiques et évolutives : application aux crinoïdes actuels (Crinoidea : Echinodermata). $W w w$.Theses.Fr.

Eléaume, M., Hemery, L. G., Roux, M., \& Améziane, N. (2014). Southern Ocean Crinoids. In Biogeographic Atlas of the Southern Ocean (pp. 208-212). Cambridge.

Felsenstein, J. (1989). PHYLIP - Phylogeny Inference Package (version 3.2). Cladistics, (5), $164-166$.

Filatov, D. A. (2019). Extreme Lewontin's Paradox in Ubiquitous Marine Phytoplankton Species. Molecular Biology and Evolution, 36(1), 4-14. http://doi.org/10.1093/molbev/msy195

Fišer, C., Robinson, C. T., \& Malard, F. (2018). Cryptic species as a window into the paradigm shift of the species concept. Molecular Ecology, 27(3), 613-635. http://doi.org/10.1111/mec.14486

Folmer, O., Black, M., Hoeh, W., Lutz, R., \& Vrijenhoek, R. (1994). DNA primers for amplification of mitochondrial cytochrome c oxidase subunit I from diverse metazoan invertebrates. Molecular Marine Biology and Biotechnology, 3(5), 294-299.

Frankham, R., Ballou, J. D., Dudash, M. R., Eldridge, M. D. B., Fenster, C. B., Lacy, R. C., et al. (2012). Implications of different species concepts for conserving biodiversity. Biological Conservation, 153, 25-31. http://doi.org/10.1016/j.biocon.2012.04.034

Fu, Y. X. (2001). Estimating mutation rate and generation time from longitudinal samples of DNA sequences. Molecular Biology and Evolution, 18(4), 620-626. http://doi.org/10.1093/oxfordjournals.molbev.a003842

Fu, Y. X., \& Li, W. H. (1993). Statistical tests of neutrality of mutations. Genetics, 133(3), 693-709.

Gascuel, O. (1997). BIONJ: an improved version of the NJ algorithm based on a simple model of sequence data. Molecular Biology and Evolution, 14(7), 685-695. http://doi.org/10.1093/oxfordjournals.molbev.a025808

Gossmann, T. I., Woolfit, M., \& Eyre-Walker, A. (2011). Quantifying the variation in the effective population size within a genome. Genetics, 189(4), 1389-1402. http://doi.org/10.1534/genetics.111.132654

Gouy, M., Guindon, S., \& Gascuel, O. (2010). SeaView version 4: A multiplatform graphical user interface for sequence alignment and phylogenetic tree building. Molecular Biology and Evolution, 27(2), 221-224. http://doi.org/10.1093/molbev/msp259

Grant, R. A., Griffiths, H. J., Steinke, D., Wadley, V., \& Linse, K. (2010). Antarctic DNA barcoding; a drop in the ocean? Polar Biology, 34(5), 775-780. http://doi.org/10.1007/s00300-010-0932-7

Griffiths, H. J. (2010). Antarctic marine biodiversity--what do we know about the distribution of life in the Southern Ocean? PloS One, 5(8), e11683. http://doi.org/10.1371/journal.pone.0011683

Griffiths, H. J., Barnes, D. K. A., \& Linse, K. (2009). Towards a generalized biogeography of the Southern Ocean benthos. Journal of Biogeography, 36(1), 162-177. http://doi.org/10.1111/j.1365-2699.2008.01979.x

Hawlitschek, O., Hendrich, L., Espeland, M., Toussaint, E. F. A., Genner, M. J., \& Balke, M. 
(2012). Pleistocene climate change promoted rapid diversification of aquatic invertebrates in Southeast Australia. BMC Evolutionary Biology, 12(1), 142.

http://doi.org/10.1186/1471-2148-12-142

Heimeier, D., Lavery, S., \& Sewell, M. A. (2010). Molecular species identification of Astrotoma agassizii from planktonic embryos: further evidence for a cryptic species complex. The Journal of Heredity, 101(6), 775-779. http://doi.org/10.1093/jhered/esq074

Hemery, L. G., Améziane, N., \& Eléaume, M. (2013a). Circumpolar dataset of sequenced specimens of Promachocrinus kerguelensis (Echinodermata, Crinoidea). ZooKeys, 315(60), 55-64. http://doi.org/10.3897/zookeys.315.5673

Hemery, L. G., Eléaume, M., Roussel, V., Améziane, N., Gallut, C., Steinke, D., et al. (2012). Comprehensive sampling reveals circumpolarity and sympatry in seven mitochondrial lineages of the Southern Ocean crinoid species Promachocrinus kerguelensis (Echinodermata). Molecular Ecology, 21(10), 2502-2518. http://doi.org/10.1111/j.1365294X.2012.05512.x

Hemery, L. G., Roux, M., Améziane, N., \& Eléaume, M. (2013b). High-resolution crinoid phyletic inter-relationships derived from molecular data. Cahiers De Biologie Marine, 54(4), 511-525.

Ho, S. Y. W., Lanfear, R., Bromham, L., Phillips, M. J., Soubrier, J., Rodrigo, A. G., \& Cooper, A. (2011). Time-dependent rates of molecular evolution. Molecular Ecology, 20(15), 3087-3101. http://doi.org/10.1111/j.1365-294X.2011.05178.x

Ho, S. Y. W., Phillips, M. J., Cooper, A., \& Drummond, A. J. (2005). Time dependency of molecular rate estimates and systematic overestimation of recent divergence times. Molecular Biology and Evolution, 22(7), 1561-1568. http://doi.org/10.1093/molbev/msi145

Hudson, R. R., \& Coyne, J. A. (2002). Mathematical consequences of the genealogical species concept. Evolution, 56(8), 1557-1565.

Hudson, R. R., Boos, D. D., \& Kaplan, N. L. (1992). A statistical test for detecting geographic subdivision. Molecular Biology and Evolution, 9(1), 138-151. http://doi.org/10.1093/oxfordjournals.molbev.a040703

Kirkpatrick, M., \& Barton, N. (2006). Chromosome inversions, local adaptation and speciation. Genetics, 173(1), 419-434. http://doi.org/10.1534/genetics.105.047985

Knowlton, N. (1993). Sibling Species in the Sea. Annual Review of Ecology and Systematics, 24(1), 189-216. http://doi.org/10.1146/annurev.ecolsys.24.1.189

Knowlton, N. (2000). Molecular genetic analyses of species boundaries in the sea. Hydrobiologia, 420(1), 73-90. http://doi.org/10.1023/A:1003933603879

Lecointre, G., Améziane, N., Boisselier, M.-C., Bonillo, C., Busson, F., Causse, R., et al. (2013). Is the species flock concept operational? The Antarctic shelf case. PloS One, 8(8), e68787. http://doi.org/10.1371/journal.pone.0068787

Lessios, H. A., Kessing, B. D., Robertson, D. R., \& Paulay, G. (1999). Phylogeography of the Pantropical Sea Urchin Eucidaris in Relation to Land Barriers and Ocean Currents. Evolution, 53(3), 806. http://doi.org/10.2307/2640720

Librado, P., \& Rozas, J. (2009). DnaSP v5: a software for comprehensive analysis of DNA polymorphism data. Bioinformatics, 25(11), 1451-1452.

http://doi.org/10.1093/bioinformatics/btp187

Lind, C. E., Evans, B. S., Knauer, J., Taylor, J. J. U., \& Jerry, D. R. (2009). Decreased genetic diversity and a reduced effective population size in cultured silver-lipped pearl oysters (Pinctada maxima). Aquaculture, 286(1-2), 12-19. http://doi.org/10.1016/j.aquaculture.2008.09.009

Linse, K., Cope, T., Lörz, A.-N., \& Sands, C. (2007). Is the Scotia Sea a centre of Antarctic marine diversification? Some evidence of cryptic speciation in the circum-Antarctic 

1068. http://doi.org/10.1007/s00300-007-0265-3 radiated: iguanid lizard clades as a case study. The American Naturalist, 160(2), 147-157. http://doi.org/10.1086/341557

Madrigal, L., Posthumously, L. C., Melendez-Obando, M., Villegas-Palma, R., Barrantes, R., Raventos, H., et al. (2012). High mitochondrial mutation rates estimated from deeprooting Costa Rican pedigrees. American Journal of Physical Anthropology, 148(3), 327333. http://doi.org/10.1002/ajpa.22052

Mahler, D. L., Ingram, T., Revell, L. J., \& Losos, J. B. (2013). Exceptional convergence on the macroevolutionary landscape in island lizard radiations. Science, 341(6143), 292-295. http://doi.org/10.1126/science. 1232392

Mayden, R. L. (1997). A hierarchy of species concepts: the denouement in the saga of the species problem.

McClintock, J. B., \& Pearse, J. S. (1987). Reproductive biology of the common antarctic crinoid Promachocrinus kerguelensis (Echinodermata: Crinoidea). Marine Biology, 96(3), 375-383. http://doi.org/10.1007/BF00412521

Meiklejohn, C. D., Montooth, K. L., \& Rand, D. M. (2007). Positive and negative selection on the mitochondrial genome. Trends in Genetics : TIG, 23(6), 259-263. http://doi.org/10.1016/j.tig.2007.03.008

Michener, C. D., \& Sokal, R. R. (1957). A quantitative approach to a problem in classification. Evolution, 11(2), 130-162. http://doi.org/10.1111/j.1558-5646.1957.tb02884.x

Moore, W., \& Robertson, J. A. (2014). Explosive adaptive radiation and extreme phenotypic diversity within ant-nest beetles. Current Biology : CB, 24(20), 2435-2439. http://doi.org/10.1016/j.cub.2014.09.022

Muschick, M., Indermaur, A., \& Salzburger, W. (2012). Convergent evolution within an adaptive radiation of cichlid fishes. Current Biology : CB, 22(24), 2362-2368. http://doi.org/10.1016/j.cub.2012.10.048

Nabholz, B., Glemin, S., \& Galtier, N. (2008). Strong variations of mitochondrial mutation rate across mammals--the longevity hypothesis. Molecular Biology and Evolution, 25(1), 120-130. http://doi.org/10.1093/molbev/msm248

Nabholz, B., Glemin, S., \& Galtier, N. (2009). The erratic mitochondrial clock: variations of mutation rate, not population size, affect mtDNA diversity across birds and mammals. BMC Evolutionary Biology, 9(1), 54. http://doi.org/10.1186/1471-2148-9-54

Palstra, F. P., \& Fraser, D. J. (2012). Effective/census population size ratio estimation: a compendium and appraisal. Ecology and Evolution, 2(9), 2357-2365. http://doi.org/10.1002/ece3.329

Palumbi, S. R. (1994). Genetic Divergence, Reproductive Isolation, and Marine Speciation. Annual Review of Ecology and Systematics, 25(1), 547-572. http://doi.org/10.1146/annurev.ecolsys.25.1.547

Pante, E., Abdelkrim, J., Viricel, A., Gey, D., France, S. C., Boisselier, M. C., \& Samadi, S. (2015). Use of RAD sequencing for delimiting species. Heredity, 114(5), 450-459. http://doi.org/10.1038/hdy.2014.105

Peccoud, J., Simon, J.-C., McLaughlin, H. J., \& Moran, N. A. (2009). Post-Pleistocene radiation of the pea aphid complex revealed by rapidly evolving endosymbionts. Proceedings of the National Academy of Sciences of the United States of America, 106(38), 16315-16320. http://doi.org/10.1073/pnas.0905129106

Pfenninger, M., \& Schwenk, K. (2007). Cryptic animal species are homogeneously distributed among taxa and biogeographical regions. BMC Evolutionary Biology, 7(1), 121. http://doi.org/10.1186/1471-2148-7-121 
Piganeau, G., \& Eyre-Walker, A. (2009). Evidence for variation in the effective population size of animal mitochondrial DNA. PloS One, 4(2), e4396. http://doi.org/10.1371/journal.pone.0004396

Pons, J., Barraclough, T. G., Gomez-Zurita, J., Cardoso, A., Duran, D. P., Hazell, S., et al. (2006). Sequence-based species delimitation for the DNA taxonomy of undescribed insects. Systematic Biology, 55(4), 595-609.

Puillandre, N., Lambert, A., Brouillet, S., \& Achaz, G. (2011). ABGD, Automatic Barcode Gap Discovery for primary species delimitation. Molecular Ecology, 21(8), 1864-1877. http://doi.org/10.1111/j.1365-294X.2011.05239.x

Rogers, A. D. (2007). Evolution and biodiversity of Antarctic organisms: a molecular perspective. Philosophical Transactions of the Royal Society B: Biological Sciences, 362(1488), 2191-2214. http://doi.org/10.1098/rstb.2006.1948

Rogers, A. D. (2012). Evolution and Biodiversity of Antarctic Organisms. In Antarctic Ecosystems (Vol. 187, pp. 417-467). Chichester, UK: John Wiley \& Sons, Ltd. http://doi.org/10.1002/9781444347241.ch14

Rowe, K. C., Aplin, K. P., Baverstock, P. R., \& Moritz, C. (2011). Recent and Rapid Speciation with Limited Morphological Disparity in the Genus Rattus. Systematic Biology, 60(2), 188-203. http://doi.org/10.1093/sysbio/syq092

Rundell, R. J., \& Price, T. D. (2009). Adaptive radiation, nonadaptive radiation, ecological speciation and nonecological speciation. Trends in Ecology \& Evolution, 24(7), 394-399. http://doi.org/10.1016/j.tree.2009.02.007

Santos, C., Montiel, R., Sierra, B., Bettencourt, C., Fernandez, E., Alvarez, L., et al. (2005). Understanding differences between phylogenetic and pedigree-derived mtDNA mutation rate: a model using families from the Azores Islands (Portugal). Molecular Biology and Evolution, 22(6), 1490-1505. http://doi.org/10.1093/molbev/msi141

Scouras, A., \& Smith, M. J. (2001). A novel mitochondrial gene order in the crinoid echinoderm Florometra serratissima. Molecular Biology and Evolution, 18(1), 61-73. http://doi.org/10.1093/oxfordjournals.molbev.a003720

Speel, J. A., \& Dearborn, J. H. (1983). Comatulid Crinoids From R/V Eltanin Cruises In The Southern Ocean. In Biology of the Antarctic Seas XIII (Vol. 38, pp. 1-60). Washington, D. C.: American Geophysical Union. http://doi.org/10.1029/AR038p0001

Strobeck, C. (1987). Average number of nucleotide differences in a sample from a single subpopulation: a test for population subdivision. Genetics, 117(1), 149-153.

Tajima, F. (1983). Evolutionary relationship of DNA sequences in finite populations. Genetics, 105(2), 437-460.

Tajima, F. (1989). Statistical method for testing the neutral mutation hypothesis by DNA polymorphism. Genetics, 123(3), 585-595.

Thatje, S., Hillenbrand, C.-D., \& Larter, R. (2005). On the origin of Antarctic marine benthic community structure. Trends in Ecology \& Evolution, 20(10), 534-540. http://doi.org/10.1016/j.tree.2005.07.010

Thatje, S., Hillenbrand, C.-D., Mackensen, A., \& Larter, R. (2008). Life hung by a thread: endurance of Antarctic fauna in glacial periods. Ecology, 89(3), 682-692.

Thornhill, D. J., Mahon, A. R., Norenburg, J. L., \& Halanych, K. M. (2008). Open-ocean barriers to dispersal: a test case with the Antarctic Polar Front and the ribbon worm Parborlasia corrugatus (Nemertea: Lineidae). Molecular Ecology, 17(23), 5104-5117. http://doi.org/10.1111/j.1365-294X.2008.03970.x

Tripati, A., Backman, J., Elderfield, H., \& Ferretti, P. (2005). Eocene bipolar glaciation associated with global carbon cycle changes. Nature, 436(7049), 341-346. http://doi.org/10.1038/nature03874

Williams, S. T., Reid, D. G., \& Littlewood, D. T. J. (2003). A molecular phylogeny of the 
Littorininae (Gastropoda: Littorinidae): unequal evolutionary rates, morphological parallelism, and biogeography of the Southern Ocean. Molecular Phylogenetics and Evolution, 28(1), 60-86. http://doi.org/10.1016/S1055-7903(03)00038-1 and absence of panmixia in the "circumpolar" crinoid Promachocrinus kerguelensis from the Atlantic sector of Antarctica. Marine Biology, 152(4), 895-904. http://doi.org/10.1007/s00227-007-0742-9

Wilson, N. G., Schrödl, M., \& Halanych, K. M. (2009). Ocean barriers and glaciation: evidence for explosive radiation of mitochondrial lineages in the Antarctic sea slug Doris kerguelenensis (Mollusca, Nudibranchia). Molecular Ecology, 18(5), 965-984. http://doi.org/10.1111/j.1365-294X.2008.04071.x

Zhang, J., Kapli, P., Pavlidis, P., \& Stamatakis, A. (2013). A general species delimitation method with applications to phylogenetic placements. Bioinformatics, 29(22), 2869-2876. http://doi.org/10.1093/bioinformatics/btt499 


\section{Tables and figures}

828 Table 1: Pairwise F-st and the probability from the Hudson et al. (1992) tests for all

829 phylogroups with 2 samples of $10+$ sequences within the same location.

830 Below diagonal: Fst. Above diagonal: probability of pamixia using the Hudson test.

\begin{tabular}{|c|c|c|c|c|c|c|c|c|c|c|c|c|}
\hline \multicolumn{10}{|c|}{ EWS } & \multirow{2}{*}{\multicolumn{3}{|c|}{$\frac{\mathrm{RS}}{\mathrm{D}}$}} \\
\hline \multicolumn{4}{|c|}{$\mathrm{C}$} & \multicolumn{3}{|c|}{$\mathrm{E}$} & \multicolumn{3}{|c|}{ G } & & & \\
\hline $\mathrm{n}=$ & 39 & 37 & 24 & & 10 & 11 & & 14 & 44 & & 27 & 26 \\
\hline & 1996 & 2000 & 2004 & & 2000 & 2004 & & 2004 & 2005 & & 2004 & 2008 \\
\hline 1996 & - & 0.035 & 0.004 & 2000 & - & 0.32 & 2004 & - & 0.40 & 2004 & - & 0.0002 \\
\hline 2000 & 0.05 & - & $<10^{-4}$ & 2004 & 0.04 & - & 2005 & 0.01 & - & 2008 & 0.21 & - \\
\hline 2004 & 0.19 & 0.47 & - & & & & & & & & & \\
\hline
\end{tabular}

831

832 


\section{Table 2: Estimation of mutation rate and effective population size}

834 Summary table of effective population sizes ( $N e$ in numbers of individuals) and mutation

835 rates ( $\mu$ per base pair per year) for each phylogroup estimated by the $\mathrm{Fu}(2001)$ method. We

836 also report the years and the number sequences used for each estimation.

\begin{tabular}{|c|ccc|cc|cc|cc|}
\hline Location & \multicolumn{5}{|c|}{ EWS } & \multicolumn{2}{|c|}{ RS } \\
\hline Phylogroup & \multicolumn{3}{|c|}{ C } & \multicolumn{2}{|c|}{ E } & \multicolumn{2}{|c|}{ G } & \multicolumn{2}{|c|}{ D } \\
$\mathrm{n}=$ & 39 & 37 & 24 & 10 & 11 & 14 & 44 & 27 & 26 \\
Dates & 1996 & 2000 & 2004 & 2000 & 2004 & 2004 & 2005 & 2004 & 2008 \\
$\mu$ & \multicolumn{2}{|c|}{$1.910^{-5}$} & 2.7 & $10^{-5}$ & 3.5 & $10^{-4}$ & 4.2 & $10^{-4}$ \\
\hline $\mathrm{Ne}$ & \multicolumn{4}{|c|}{4.0} & 7.0 & 1.7 & 2.6 \\
\hline
\end{tabular}

837 
839 Fig. 1: Phylogenetic representation of the 1797 COI sequences from P. kerguelensis and

840 F. mawsoni. The tree was inferred using BIONJ on the unique sequences. Each square

841 represents one sequence. The phylogroups are the ones used in the analysis (mostly ABGD

842 groups) and both supplementary splits proposed by PTP are indicated as C1/C2 and E1/E2.

843 The colors represent the different phylogroups considered in this study. The boxes and the

844 numbers refer to the number of individuals carrying the haplotype.

845

846 Fig. 2: Genetic turn over at the RS ( $a$ and b) and EWS (c and d) locations. The pie charts (a

847 and c) represent the number of phylogroups at different years in the locations, with the same

848 colors code as in Figure 1. The heatmaps (b and d) represents P-values of the Hudson et al.

849 (1992) tests for genetic structure within a phylogroup of each location.

850

851 Fig. 3: Distribution of p-values for different neutrality tests on the 1,624 sequences tested for 852 group with at least 10 sequences. From left to right: Tajima D (1983), Fu and Li D* (1993), 853 Fu and Li F* (1993), Achaz Y* (2008) and Strobeck S (1987).

854

855 Fig. 4: Simulation of migration effect on Ne estimation.

856

857 Fig. 5: Divergence time of the different phylogroup of the P. kerguelensis complex. The

858 depth of the triangles represents the maximum diversity within each phylogroup. The time is 859 indicated in years before present. The timescale on the top is assuming a mutation rate of $8608.10^{-5}$ mutation/bp/year. The timescale on the bottom is assuming a mutation rate of $8.10^{-3}$ 861 mutation/bp/year. 


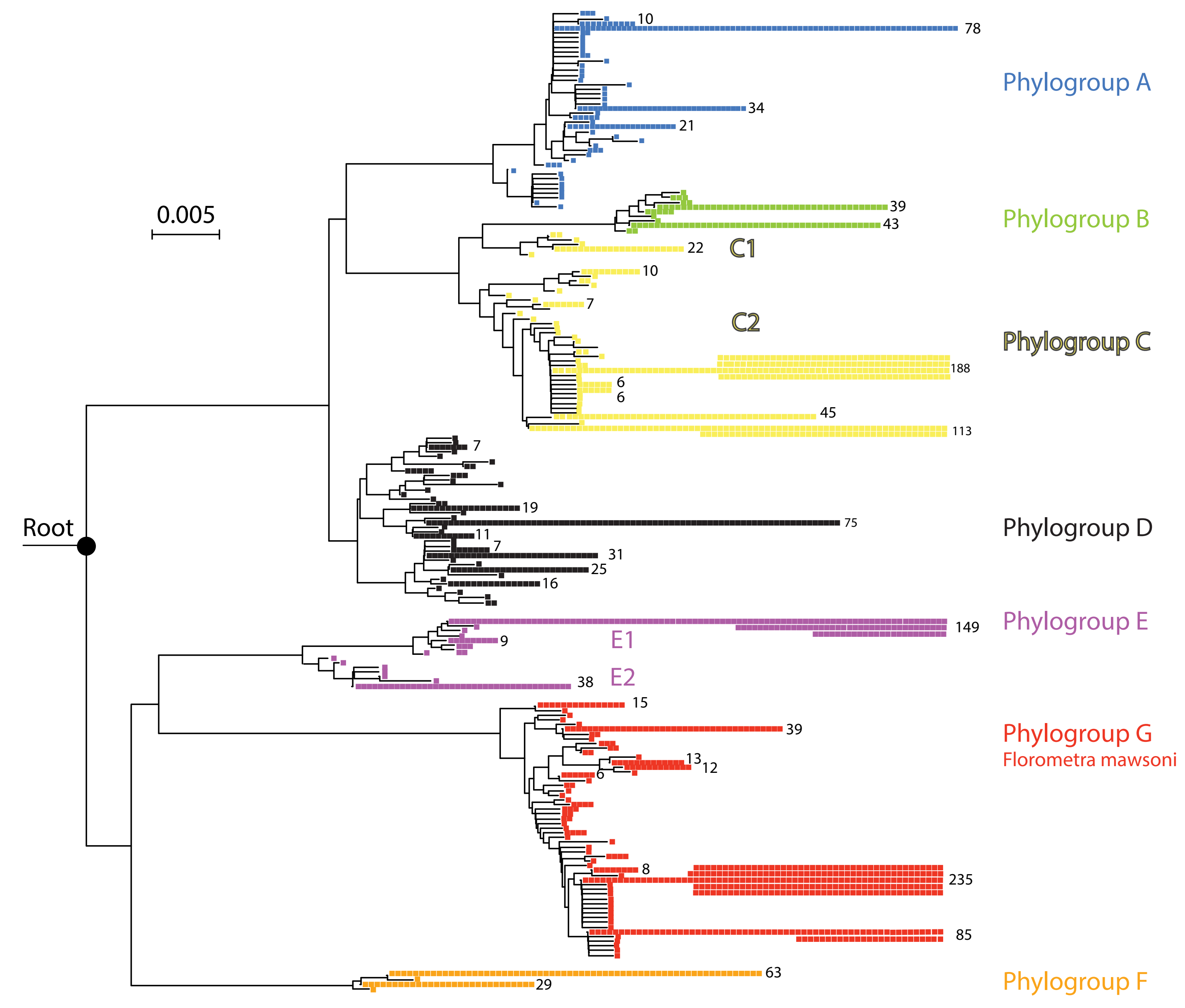


a)

\section{Ross Sea}

East Weddle Sea b)

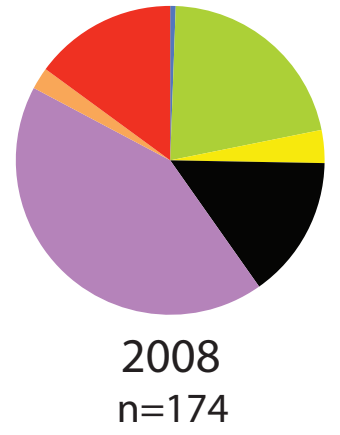

d)

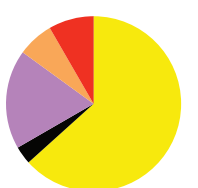
2002 $n=56$

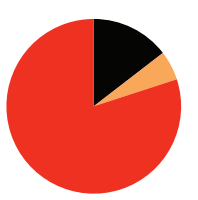

2005 $\mathrm{n}=55$

within phylogroup D 2008 2004
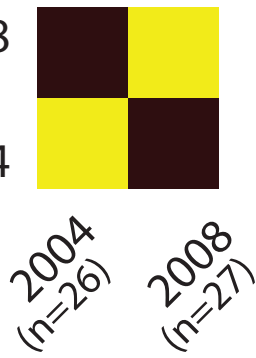

1996

$\mathrm{n}=59$

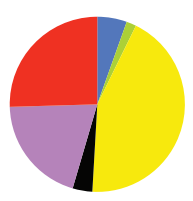

2004 $\mathrm{n}=55$

phylogroup

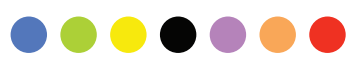

A B C D F E G within phylogroup C

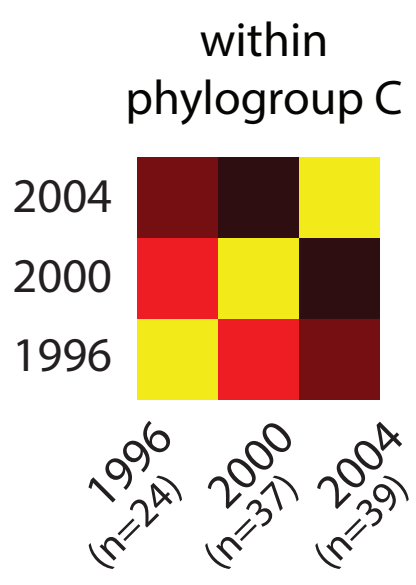

P-value

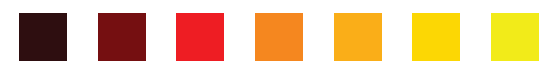

ڤ. 


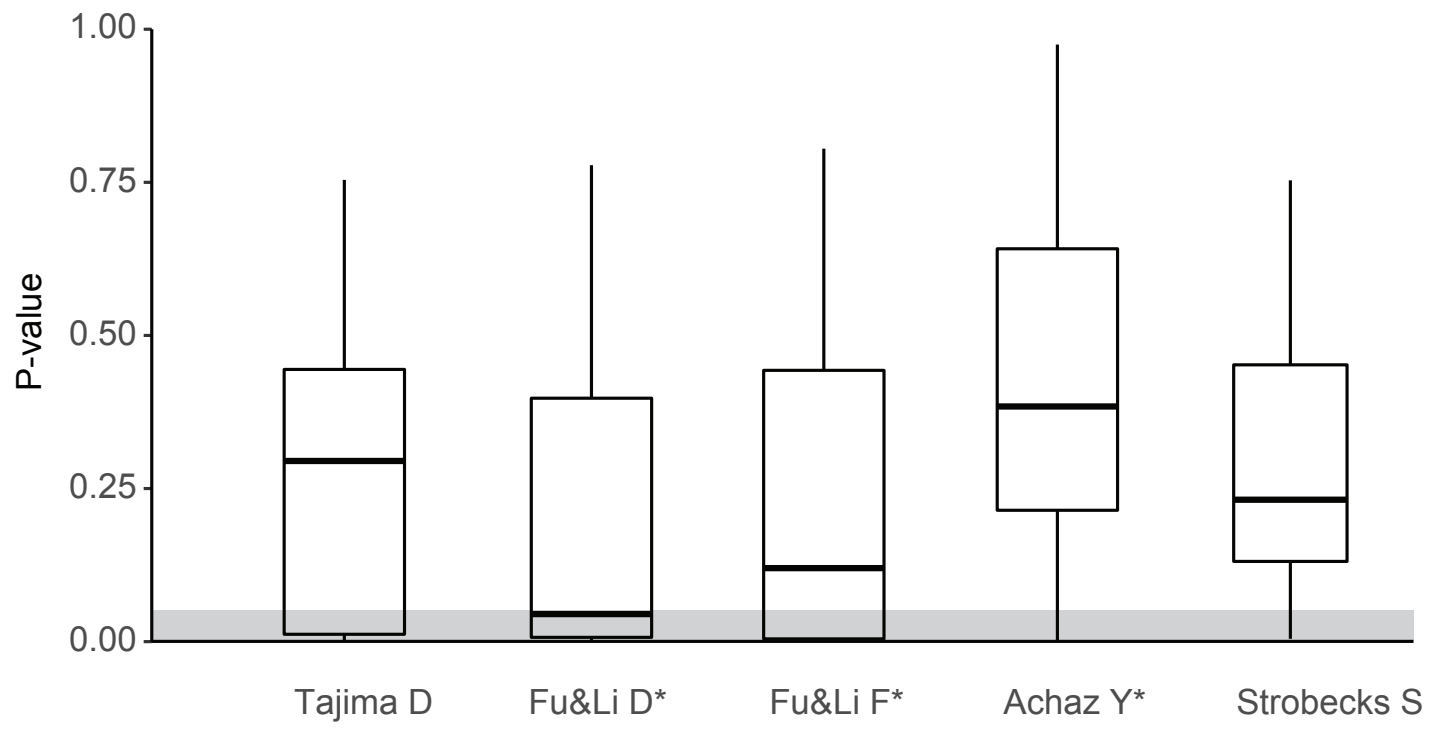


Estimated relative effective population size $(\widehat{\mathrm{Ne}})$

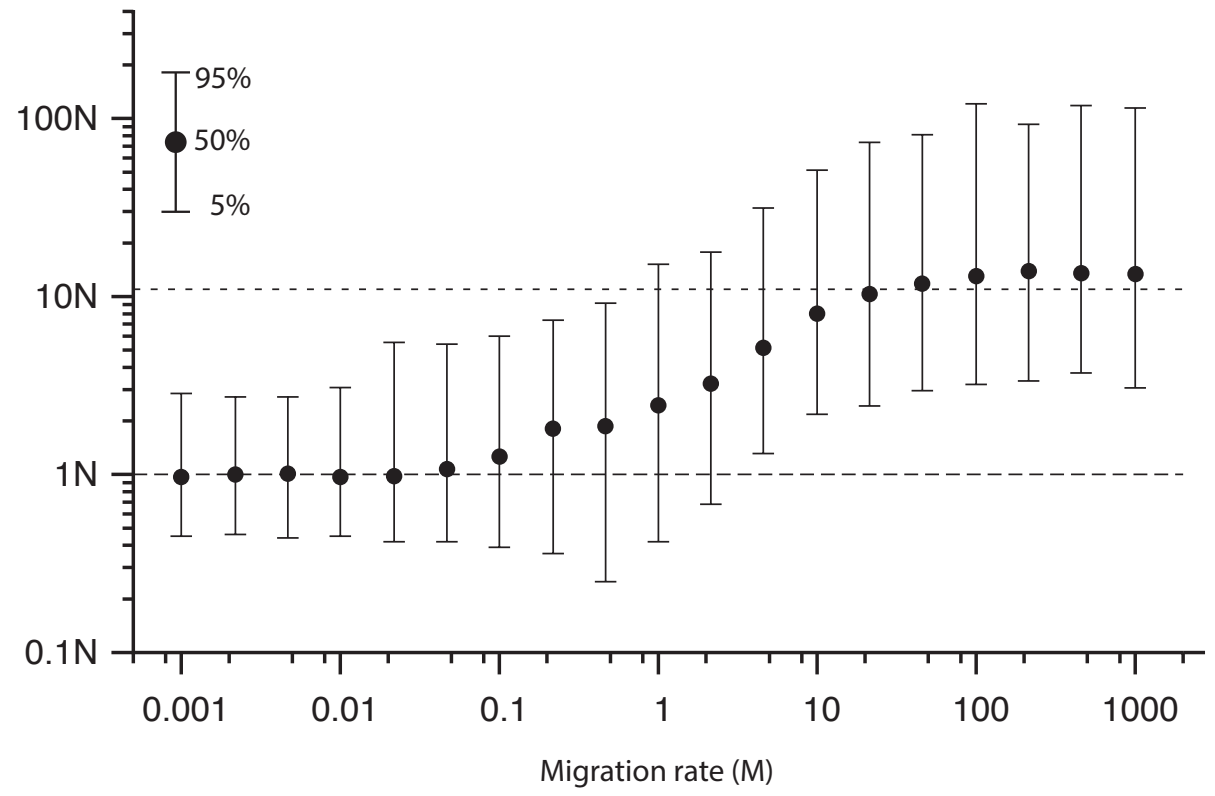




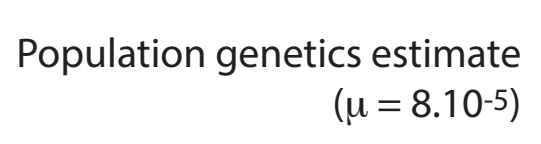

Lessios (1999) estimate $\quad$ 106

$$
\left(\mu=3.10^{-8}\right)
$$

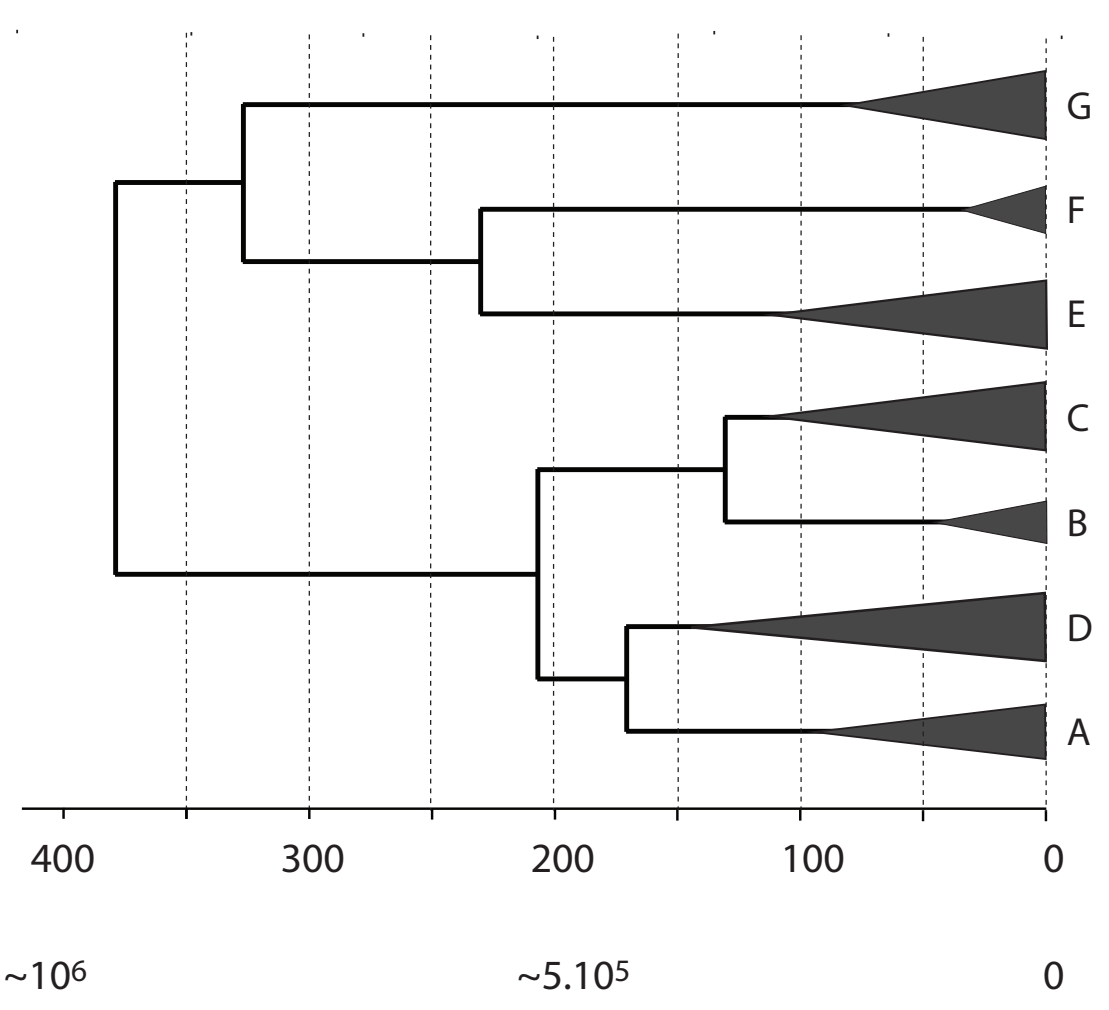

Years 